\title{
A critical review of the literature on social and leisure activity and wellbeing in later life
}

\author{
KATHRYN BETTS ADAMS*, SYLVIA LEIBBRANDT* \\ and HEEHYUL MOON*
}

\begin{abstract}
An engaged lifestyle is seen as an important component of successful ageing. Many older adults with high participation in social and leisure activities report positive wellbeing, a fact that fuelled the original activity theory and that continues to influence researchers, theorists and practitioners. This study's purpose is to review the conceptualisation and measurement of activity among older adults and the associations reported in the gerontological literature between specific dimensions of activity and wellbeing. We searched published studies that focused on social and leisure activity and wellbeing, and found 42 studies in 44 articles published between I 995 and 2009. They reported from one to I 3 activity domains, the majority reporting two or three, such as informal, formal and solitary, or productive versus leisure. Domains associated with subjective wellbeing, health or survival included social, leisure, productive, physical, intellectual, service and solitary activities. Informal social activity has accumulated the most evidence of an influence on wellbeing. Individual descriptors such as gender or physical functioning sometimes moderate these associations, while contextual variables such as choice, meaning or perceived quality play intervening roles. Differences in definitions and measurement make it difficult to draw inferences about this body of evidence on the associations between activity and wellbeing. Activity theory serves as shorthand for these associations, but gerontology must better integrate developmental and psychological constructs into a refined, comprehensive activity theory.
\end{abstract}

$\boldsymbol{K E Y} \boldsymbol{W} \boldsymbol{W} \boldsymbol{R} \boldsymbol{S}-$ activity theory, social activity, leisure activity, wellbeing, literature review.

\section{Introduction}

An engaged lifestyle is widely regarded as an important component of successful ageing. Many older adults with active participation in social and leisure activities report positive wellbeing, a fact which stimulated the original activity theory of ageing and continues to influence contemporary

* Mandel School of Applied Social Sciences, Case Western Reserve University, Cleveland, Ohio, USA. 
researchers and practitioners. Numerous studies examining associations between social or leisure activity participation and aspects of wellbeing are represented in the ageing literature. In this article, we undertake a critical review of the literature, examine the conceptualisation and measurement of activity among older adults and consider the implications and prospects for a more comprehensive activity theory.

\section{Activity and wellbeing in gerontology}

The activity theory of ageing began with the simple propositions that wellbeing in older adults is promoted by (a) higher levels of participation in social and leisure activities, and (b) role replacement when roles must be relinquished (Havighurst I96I). As one of the first and most influential theories of adjustment to ageing, activity theory caught the collective imagination of gerontological practitioners and researchers alike, appealing in its optimism about the possibilities for later life. Further development of the theory occurred during the early I970s as investigators distinguished three broad types of social and leisure activity participation: informal, interacting socially with familiar people such as relatives, friends or neighbours; formal, participation in formal groups and organisations; and solitary, activities one does alone like reading, television viewing and many hobbies. Findings suggested that activity theory might be revised to emphasise informal social activity, which was shown to influence wellbeing more than formal or solitary activity (Lemon, Bengtson and Peterson 1972; Longino and Kart I982).

Increased longevity means that many more individuals now reach advanced old age than ever before. Retirement pensions and insurance that have improved the economic standing of many older adults, along with better health care and nutrition, offer present cohorts of middle-aged and older adults greater opportunities for prolonged health and wellbeing, and cast late life in a new light. Furthermore, since the ig7os social roles have become more fluid among middle-aged and older adults, also casting activity theory in a new light. As we face the increasing demographic imperative of an ageing population, activity theory seems at once outdated and yet very relevant. Its influence continues today in the 'successful ageing' paradigm. Rowe and Kahn's (1998) report of the McArthur Foundation's research posed a definition of successful ageing that featured social engagement as one of three major elements. They defined social engagement in two ways: 'remaining involved in activities that are meaningful and purposeful' and 'maintaining close relationships', therefore emphasising productive and social aspects of activity for successful ageing. 
Gerontology scholars propose a number of means by which social and leisure participation may maintain or promote wellbeing in older adults. These include the obvious physical benefits from any activity that involves movement - the stimulation of bodily systems promotes a greater range of motion and muscle tone, and internal benefits to digestion and cardiovascular health. Extensive documentation of the health benefits of physical activity for older adults is found in the medical, nursing, physical therapy and occupational therapy literatures (e.g. Hogan 2005; Lim and Taylor 2004). Social support pathways - both emotional closeness and instrumental assistance - offer another important means through which social and leisure participation enhances wellbeing (Aquino et al. I996). Social support may also reduce stress by promoting cognitive reappraisals that make stressful situations less stressful (Lazarus and Folkman I984). Social interactions with family, groups or community may lead to social integration that promotes a sense of belonging and establishes or maintains positive interpersonal attachments (Hagrety et al. I996). Related to this is the manner in which social interaction and integration promotes the exchange of health information, persuasion and support that may directly persuade individuals to change health-related behaviours (Berkman et al. 2000).

On an individual level, role continuity or role replacement through appropriate activity participation and with familiar, supportive others may contribute to the individual's sense of meaning or purpose and to maintenance of a sense of identity (Atchley ig89; Lemon, Bengtson and Peterson I972). And finally, activity participation frequently involves the pursuit or achievement of personal goals, thus adding to a sense of personal mastery or accomplishment (Holahan I988; Lawton I993; Lawton et al. 2002; Warr, Butcher and Robertson 2004). These potential benefits of social and leisure activity in later life are intuitively appealing, yet it is unclear whether different types of activity are equally important for the wellbeing of older adults, or for all groups of older adults.

Defining wellbeing among older adults has received its own due attention ( $c f$. Hilleras, Aguero-Torres and Winblad 200г; Stanley and Cheek 2003). Outside of gerontology, research on subjective wellbeing has expanded into positive psychology and tends to emphasise happiness, contentment, and satisfaction with the past, current life, and future (Diener et al. I999). In gerontology, wellbeing has been said to be the subjective counterpart of a more public evaluation of 'successful ageing' (Stanley and Cheek 2003). Because of the variety of definitions and measures used by researchers in the gerontology literature, this review has necessarily taken an inclusive approach to the definition of 'wellbeing', with constructs such as life satisfaction, happiness, positive affect, or quality of life. In later life, 
physical health and the nearness to death become more important than they may be in earlier life. Thus, global health measures such as self-rated health frequently appear in studies of activity and wellbeing relationships, and several longitudinal studies have used time till death as the ultimate objective measure of the effects of activity participation in later life. Although strictly speaking, survival or longevity goes beyond the scope of subjective wellbeing, these studies reflect a closely related way of capturing information on the potentially ameliorative effects of activity participation and are particularly relevant to gerontology research.

The current review focuses on the conceptualisation and measurement of the activities that comprise social and leisure participation among older adults, on the associations of these activities with subjective wellbeing, health and survival, and on the implications for theory and research in gerontology. Researchers have attempted to find universals as well as mediating and moderating factors in the activity/wellbeing paradigm. Furthermore, studies on activity and wellbeing among older adults present numerous ways of defining and measuring social and leisure activity and numerous wellbeing outcomes. The variety of different activity dimensions generates a confusing array of outcomes, which suggests the need to summarise and synthesise this literature. Hence, in this critical review of the recent literature on activity and health or wellbeing outcomes in later life, our aims are to identify domains of social and leisure activity participation, the methods used in measures of activity in later life, and extant evidence on the relationship of social and leisure activity participation to subjective wellbeing, health and survival in later life.

\section{Methods}

We searched five databases, PsycInfo, AgeLine, Medline, Academic Search Premiere and CINHAL, as well as article reference lists for original research articles published in English in peer-reviewed journals that described naturalistic (non-intervention) studies with a focus on social or leisure activity among non-institutionally resident older adults published from 1995 to 2009. We targeted recent research to find studies using rigorous methods that have become more common since the early ig9os and to update the knowledge base in this area for relevance to current and coming cohorts. We used the following search terms:

- Activity, social activity, leisure activity, recreation, or activity theory.

- Older adult, age, ageing, seniors, or elder.

- Wellbeing, health, or mental health. 
Other criteria for inclusion in this review were: the study had to use a measure of social and/or leisure activity among older adults, and model the relationship of activities to other variables with a focus on subjective wellbeing (e.g. self-reports of life satisfaction, happiness, positive affect, freedom from depression, general health or functioning measures), or survival. Health was not the major focus but seen as a component of wellbeing; other studies focused on length of survival as an ultimate measure of wellbeing. We included cross-sectional and longitudinal studies, but chose only studies in which statistical covariates and/or grouping variables were used to control for effects of socio-demographic attributes or other variables that might associate with wellbeing, health or survival. In the spirit of activity theory and given the theoretical importance of social and leisure activity, we omitted studies that examined only physical activity or productive activity, such as volunteer or paid employment, without considering them within the larger context of social or leisure participation. Finally, we did not include the growing literature on the effects of activity participation on cognitive functioning (or conversely, dementia), because we see measures of cognitive abilities as quite distinct from subjective wellbeing or survival. Furthermore, studies focusing on cognitive outcomes often retrospectively examine years of occupational and leisure activity from younger and middle adulthood to identify effects in later life, which clearly takes these studies outside the realm of the activity theory of ageing.

After the database search and selection process, we read completely all the selected studies and coded them for several key methodological characteristics: sample size and composition; study design (cross-sectional or longitudinal and length of time for the latter); domains of activity/social participation and individual activities measured, if given; measures of wellbeing, health or survival; moderating variables examined in the study; outcome variables related to wellbeing, health, or survival; relevant findings regarding the relationship of social and leisure participation to wellbeing, health or survival.

\section{The results}

The final database includes 42 studies reported in 44 peer-reviewed journal articles that modelled the relationship of activity participation among older adults to some form of wellbeing, general health or survival. Of the 42 studies, 24 were cross-sectional and 18 longitudinal. The longitudinal studies spanned from four to 20 years (mean 8.6). All of these studies 
included both male and female participants, and all were published in English in peer-reviewed journals. They represented Spain, Germany, The Netherlands, Finland, Sweden, Japan, China, Taiwan, Israel, Great Britain and the United States of America. Primary or secondary analyses of large datasets were tapped for several of these studies, including the Berlin Study of Ageing, the Baltimore Longitudinal Study of Ageing, and the Americans Changing Lives study. A small minority of the studies presented data from samples of less than Ioo, which may suggest there was insufficient power for some statistical tests, but most had well over 200 participants, and 13 of the studies included over I,ooo. Table $\mathrm{I}$ is a list of the studies with selected information about key variables and outcomes.

\section{Activity classification}

We defined activity domains as the categories used in measures of activity in later life. For instance, social, leisure or productive each represent domains which encompass a number of individual activities. Not all studies identified distinct domains; those that appear with only one domain in Table I grouped all activities measured under the label 'leisure' or 'social' and did not categorise them. Among the 42 individual studies, the number of identified domains ranged from one to 13 (mean 3.8). Investigators sometimes used different names to represent the same constructs. For instance, leisure activities were called 'consumptive' by some. 'Regenerative' activities were those that were necessary to everyday life, which also were termed 'obligatory' by some. We grouped similar domains with unique names to arrive at seven general activity domains, as follows: Social (in some studies, further specified as Informal or Formal), Leisure, Productive, Physical, Intellectual/Cultural, Solitary, Spiritual/Serving Others. In addition to these, several of the studies included some sort of evaluation of quality or satisfaction with activity participation, Quality/Satisfaction.

Various domain sets group these categories in ways that represent different perspectives on activity participation, dividing up the universe of possible activities according to certain criteria. Each domain set distinguishes different characteristics of social and leisure activity. For instance, the domain set social and solitary divides activity according to the social context. Theoretically, any activity could be classified as either social or solitary, although many aspects of the activities would not be captured. Among the domain sets reported were formal, informal and solitary; intellectual, physical, and social; productive and leisure; formal, informal and physical; in-home and out-of-home; and regenerative, productive and consumptive. 
T A B L E I. Study designs, sample sizes, activity domains, outcomes and key findings

\begin{tabular}{|c|c|c|c|c|}
\hline Authors (year) & Design & Activity domains & Outcome measures & Key findings ${ }^{1}$ \\
\hline $\begin{array}{l}\text { Agahi and } \\
\text { Parker (2008) }\end{array}$ & $\mathrm{LS}$, I2 years, $\mathrm{N}=\mathrm{I} 246$ & $\begin{array}{l}\text { I Domain: leisure (reading, hobbies, } \\
\text { gardening, fishing/hunting, attending } \\
\text { cultural events, study circles or courses, } \\
\text { dancing, choir singing, playing music, } \\
\text { attending other organised activities, } \\
\text { religious services) }\end{array}$ & Survival & $\begin{array}{l}\text { Greater participation in cultural activities } \\
\text { reduced mortality risk for both genders. } \\
\text { Women's survival most influenced by } \\
\text { higher participation in study circles and } \\
\text { organised activities (informal and formal } \\
\text { social), and by reading, whereas men's } \\
\text { responded most to gardening and } \\
\text { hobbies (solitary). }\end{array}$ \\
\hline Everard (I999) & $\mathrm{N}=249$ & $\begin{array}{l}6 \text { Reasons for activity: I. fun; 2. mental; } \\
\text { 3. social; 4. pass the time; } 5 \text {. obligatory; } \\
\text { 6. physical }\end{array}$ & $\begin{array}{l}\text { Positive affect, } \\
\text { negative affect }\end{array}$ & $\begin{array}{l}\text { Engaging in more activities for social } \\
\text { reasons associated with positive affect. } \\
\text { A greater proportion of activities engaged } \\
\text { in 'to pass the time' associated with } \\
\text { negative affect. }\end{array}$ \\
\hline $\begin{array}{l}\text { Everard et al. } \\
(2000)\end{array}$ & CSS, $\mathrm{N}=244$ & $\begin{array}{l}4 \text { Domains: I. instrumental (shopping, } \\
\text { paying bills, doing housework, and } \\
\text { cooking); 2. social (travelling, } \\
\text { entertaining, attending parties, attending } \\
\text { church); 3. high-demand leisure activities } \\
\text { (swimming, woodworking, walking, } \\
\text { gardening); 4. low-demand leisure } \\
\text { activities (sewing, reading, TV, music) }\end{array}$ & $\begin{array}{l}\text { Physical health, } \\
\text { mental health }\end{array}$ & $\begin{array}{l}\text { Instrumental, social and high-demand } \\
\text { leisure activities associated with physical } \\
\text { health. Low-demand leisure activities } \\
\text { associated with mental health. }\end{array}$ \\
\hline $\begin{array}{l}\text { Fernandez, } \\
\text { Azmarron } \\
\text { and Ruiz } \\
(200 \mathrm{I})\end{array}$ & $\mathrm{CS}, \mathrm{N}=507$ & $\begin{array}{l}4 \text { Domains: I. physical; } 2 \text {. leisure } \\
\text { ( } 5 \text { activities; } 3 \text {. satisfaction with activities; } \\
\text { 4. social contacts }\end{array}$ & Life satisfaction & $\begin{array}{l}\text { Among psycho-social variables, leisure } \\
\text { participation, activity satisfaction and } \\
\text { social contacts combined into a single } \\
\text { activity factor which had significant } \\
\text { relationship to life satisfaction. }\end{array}$ \\
\hline $\begin{array}{l}\text { Fortuijn et al. } \\
(2006)\end{array}$ & $\begin{array}{l}\text { CS, } 6 \\
\text { Europeancountries }^{2}\end{array}$ & $\begin{array}{l}3 \text { Domains: I. home-based, family- } \\
\text { oriented; } 2 \text {. out-of-home, individualistic } \\
\text { activities; } 3 \text {. out-of-home, local } \\
\text { community participation }\end{array}$ & $\begin{array}{l}\text { Satisfaction with } \\
\text { activity involvement }\end{array}$ & $\begin{array}{l}\text { Level of satisfaction related to out- } \\
\text { of-home activities for } 60-80 \text {-year-old } \\
\text { group; participation in home-based } \\
\text { activities for } 80-90 \text {-year-old group. }\end{array}$ \\
\hline
\end{tabular}


TA B L E I. (Cont.)

\begin{tabular}{|c|c|c|c|c|}
\hline Authors (year) & Design & Activity domains & Outcome measures & Key findings ${ }^{1}$ \\
\hline $\begin{array}{l}\text { Glass et al. } \\
\text { (I999) }\end{array}$ & $\mathrm{LS}, \mathrm{I} 3$ years, $\mathrm{N}=276 \mathrm{I}$ & $\begin{array}{l}3 \text { Domains: I. social (church attendance; } \\
\text { visits to cinema, restaurants, sporting } \\
\text { events; day or overnight trips; playing } \\
\text { cards, games, bingo; participation in } \\
\text { social groups); 2. fitness (active sports or } \\
\text { swimming; walking; physical exercise); } \\
\text { 3. productive (gardening; preparing } \\
\text { meals; shopping; unpaid community } \\
\text { work; paid community work; and other } \\
\text { paid employment) }\end{array}$ & Survival & $\begin{array}{l}\text { Increased social, fitness, productive } \\
\text { activity predicted longer survival. }\end{array}$ \\
\hline
\end{tabular}

Glass et al. LS, 6 years, $\mathrm{N}=\mathrm{I} 970 \quad 3$ Domains: $\mathrm{I}$. prod

(2006)

Harlow and
Cantor (I996)

Herzog et al. CS, $\mathrm{N}=679$

(I998)
8 Domains: I. social; 2. mass

communication use; 3 . building

knowledge; 4 . home and hobbies;

5. creative (playing or singing with a

musical group; creative writing, painting,

sculpture, or dramatics; playing a musical

instrument); 6. activities outside home;

7. community service; 8 . games

2 Domains: I. productive (run errands,

grocery shopping, housework, shopping);

2. leisure (volunteer work, attendance at

meetings, movies/plays/concerts, classes/

lectures, travel, sports and exercise)
Cross-sectional association of social engagement (productive and social participation); longitudinal association only for those with fewer depressive symptoms at baseline, suggesting a preventive, but not ameliorative effect.

Life satisfaction

Community service, social, and

media/communication activities; being retired led to greater importance of activities to wellbeing for men.

Wellbeing

Frequency of productive and leisure activities; 'Agentic self-concept' and social sense of self increased the activity/wellbeing relationship. 


\begin{tabular}{|c|c|}
\hline $\begin{array}{l}\text { Hilleras et al. } \\
\text { (I999) }\end{array}$ & $\mathrm{CS}, \mathrm{N}=\mathrm{IO} 5$ \\
\hline $\begin{array}{l}\text { Hong, Hasche } \\
\text { and Bowland } \\
(2009)\end{array}$ & LS, 6 years, $\mathrm{N}=5294$ \\
\hline $\begin{array}{l}\text { Jacobs et al. } \\
\text { (2008) }\end{array}$ & LS, 8 years, $\mathrm{N}=337$ \\
\hline Jang et al. (2004) & CS, $N=354$ \\
\hline $\begin{array}{l}\text { Janke and } \\
\text { Davey (2006); } \\
\text { Janke } \text { et al. } \\
(2006)\end{array}$ & LS, 8 years, $\mathrm{N}=\mathrm{I} 9 \mathrm{II}$ \\
\hline $\begin{array}{l}\text { Janke, Nimrod } \\
\text { and Kleiber } \\
(2008 a \\
2008 b)\end{array}$ & $\begin{array}{c}\mathrm{LS}, 8 \text { years, } \mathrm{N}=\mathrm{I} 54 \\
\text { widows aged } 50+\end{array}$ \\
\hline
\end{tabular}

3 Domains: I. intellectual; 2. social; 3. physical

I Domain: I. social activities (working, volunteering, religious services, exercise, getting together, talking on phone, going to sports/movies, and eating out), perceived adequacy.

I Domain: reading daily

2 Domains: I. informal social (talking on the phone, visiting friends); 2. formal social (taking courses or participating in discussion groups, going to social clubs, attending church or synagogue)

3 Domains: I. informal social; 2. formal social; 3 . physical leisure

3 Domains: I. informal social (talking to friends and family, visiting with friends and family); 2. formal social (participating in clubs or organisations, religious activities); 3. physical (walking, gardening, physical exercise, sports)
Positive affect, negative affect, life satisfaction

Depression

Survival

Life satisfaction

Depression, health

\section{Physical and}

subjective wellbeing ${ }^{4}$
Positive associations of wellbeing with physical activity but no correlation with social or intellectual activity (in subjects over age 9o)

Volunteering and exercising individually associated with lower depression at baseline and less increase. Those engaged in the most overall social activity (getting together, talking with others, going to sports/movies and eating out) less likely to be depressed initially, and their depression decreased across the three waves.

Reading daily at baseline (women $66 \%$, men $59 \%$ ) predicted reduced mortality among men but not women, after controlling for demographic and health variables.

Greater social activity participation was associated with greater life satisfaction among people with disability or chronic illness.

Participation in physical leisure, formal leisure and informal leisure activities predicted less depression. Optimising formal leisure also was predictive of less depression.

Reductions in social activities after being widowed associated with functional impairment, depressive symptoms and lower life satisfaction. More support for wellbeing influencing activity involvement than for activity influencing wellbeing. 


\begin{tabular}{|c|c|c|}
\hline Authors (year) & Design & Activity domains \\
\hline $\begin{array}{l}\text { Janke, Payne } \\
\text { and Van } \\
\text { Puymbroeck } \\
(2008)\end{array}$ & $\mathrm{LS}, 3^{-8}$ years, $\mathrm{N}=535$ & $\begin{array}{l}2 \text { Domains; I. informal social leisure } \\
\text { (talking by phone or getting together with } \\
\text { friends, neighbours and relatives); } \\
\text { 2. formal social leisure (attending } \\
\text { meetings, programmes or clubs; attending } \\
\text { religious services) }\end{array}$ \\
\hline Klumb (2004) & $\begin{array}{l}\mathrm{CS} \text {, time sampling, } \\
\mathrm{N}=8 \mathrm{I}\end{array}$ & $\begin{array}{l}3 \text { Domains: I. regenerative (e.g. resting, } \\
\text { eating); } 2 . \text { consumptive (e.g. meeting } \\
\text { friends, reading a novel or watching } \\
\text { television); } 3 . \text { productive (e.g. doing } \\
\text { laundry, cleaning, running errands). } \\
\text { Alone or with others }\end{array}$ \\
\hline $\begin{array}{l}\text { Lampinen et al. } \\
(2006)\end{array}$ & $\begin{array}{l}\mathrm{LS}, 8 \text { years, } \mathrm{N}=\mathrm{I} 224 \text { at } \\
\mathrm{T}_{\mathrm{I}}, \mathrm{N}=663\end{array}$ & $\begin{array}{l}2 \text { Domains: I. physical (chores, regular } \\
\text { walking, strenuous exercise); } 2 \text {. leisure } \\
\text { (participation in nine activities, including } \\
\text { active art, art appreciation, associations, } \\
\text { religious activities, handicrafts, reading, } \\
\text { study) }\end{array}$ \\
\hline $\begin{array}{l}\text { Lawton et al. } \\
(2002)\end{array}$ & $\mathrm{CS}, \mathrm{N}=600$ & $\begin{array}{l}6 \text { Domains: I. ADLs; } 2 \text { active recreation; } \\
\text { 3. other-oriented activities; } 4 \text {. intellectual; } \\
\text { 5. home planning; } 6 \text {. spiritual moral }\end{array}$ \\
\hline
\end{tabular}

Outcome measures

Key findings ${ }^{1}$

Disablement process ${ }^{5}$

\section{More frequent involvement in informal} and formal social leisure activities

significantly associated with less disability, less cognitive impairment and fewer depressive symptoms over time. Both types of leisure moderated the relationships identified in the disablement process.

Positive affect

Mental wellbeing: depression, anxiety, loneliness, mental vigour, meaning in life

Positive affect,

depression, valuation of life 
Silverstein

(200I)

Li et al. (2006) CS, N= I5 $5^{16}$

Litwin (2000)

CS, $\mathrm{N}=\mathrm{I} 7 \mathrm{O}$

Litwin and

Shiovitz-Ezra

(2006)

Litwin (2006)

CS, $\mathrm{N}=609$

Maier and

Klumb (2005)

Menec (2003)

LS I3 years, $\mathrm{N}=473$

LS, 6 years, $\mathrm{N}=\mathrm{I}, 439$
4 Domains: I. social-friendship;

2. social-cultural; 3. solitary-sedentary;

4. solitary-active

Domains: I. attending social groups; 2. recreational outings; 3 . active amusements; 4 . passive amusements ; 5. talking with friends; 6 . visiting family; 7. reading

3 Domains: I. formal; 2. informal; 3. solitary activities; supportiveness of social network

3 Domains: I. formal; 2. informal; 3. solitary activities; quality of social relationships

I Domain: leisure (going on trips, playing cards, reading books, reading newspapers, doing crafts, watching TV, listening to radio); type of social network

3 Domains: I. regenerative; 2 . productive 3. consumptive activities

3 Domains: I. social (visiting family or relatives); 2. solitary (collecting, hobbies); 3. productive (volunteer work, light housekeeping, gardening)

Morgan and LS, 4 and 8 years,

5 Domains: I. indoor; 2. outdoor leisure; 3. walking; 4. actual social (visits, talks); 5. virtual social (TV viewing, writing letters
Survival

Successful ageing ${ }^{6}$

Subjective wellbeing

\section{Wellbeing (General Health \\ Questionnaire I2)}

Morale

Survival

Happiness,

functioning, survival, life satisfaction

Life satisfaction and depressive symptoms
Greater participation in solitary-active activities significantly reduced the risk of mortality in men. None of domains was significant in women when health was controlled.

Successful ageing significantly related to greater participation in seven measured types of leisure activity, after controlling for age, gender and marital status (men, younger age and being married were more likely to be successful agers.)

'Social network supportiveness' aspect of activity associated with subjective

wellbeing, not the activity per se.

Quality of social relationships predicted wellbeing, explaining more of the

variation than informal social activity. Solitary and formal activity had no independent effects.

Morale positively associated with reading books and trips. In path analysis, morale significantly predicted by overall leisure activity levels and being in a robust social network.

Social context, 'with friends' predicted longer survival.

Level of informal social and productive activities related to happiness, functioning and survival. Solitary activities were related to happiness. No activities related to life satisfaction.

Social engagement, walking and indoor activity predicted life satisfaction. Social and outdoor activity predicted less depression. 


\begin{tabular}{|c|c|}
\hline Authors (year) & Design \\
\hline $\begin{array}{l}\text { Mullee et al. } \\
(2008)\end{array}$ & $\mathrm{LS}, 20$ years, $\mathrm{N}=3^{2}$ \\
\hline $\begin{array}{l}\text { Neugebauer, } \\
\text { Katz and } \\
\text { Pasch (2003); } \\
\text { Katz and } \\
\text { Yelin (200I) }\end{array}$ & $\mathrm{LS}, 4$ years, $\mathrm{N}=43^{6}$ \\
\hline $\begin{array}{l}\text { Nimrod and } \\
\text { Adoni (2006) }\end{array}$ & CS, $\mathrm{N}=383$ \\
\hline
\end{tabular}

3 Domains: r. housework (washing clothes, gardening, indoor plants); 2. leisure (reading, TV/radio, sedentary hobbies, physical activities, sedentary hobbies, physical activities, community social activities, pet care, visiting relatives, clubs and events); 3. walking; evaluation of activity

I3 Domains: I. housework/cooking;

2. nurturing activities; 3 . home

maintenance; 4. social interaction; 5. social events; 6 . entertainment; 7. sedentary leisure; 8 . recreational activities/hobbies/crafts; 9 . transportation; Io. religious activities; II. shopping/errands; I2. doing for others; I3. work; value of activities

I3 Domains: I. high culture; 2. popular culture; 3 . spirituality and enrichment; 4. following generation; 5 . newspapers; 6. free outdoor activities; 7. computer;

8. friends; 9. 'forever young'; Io. origin family; ir. independent home;

I2. neighbours; I3. games; satisfaction with leisure

2 Domains: I. continued leisure;

2. innovative leisure

Outcome measures

Key findings ${ }^{1}$

Survival

Increased survival associated with increased activities summed score and better activity self-evaluation for males; increased survival with better activity self-evaluation only for females.

Satisfaction with abilities, depressive symptoms

Life satisfaction, leisure satisfaction

Life satisfaction
Less disability in valued activities, and favourable social comparisons predicted greater satisfaction with abilities, which was the most important predictor of less depression.

Leisure satisfaction was found to affect life satisfaction; greater levels of participation in high culture, popular culture and spirituality and enrichment activities indirectly influenced life satisfaction.

Innovators had significantly higher life satisfaction than non-innovators. 


$\begin{array}{ll}\begin{array}{l}\text { Onishi et al. } \\ (2006)\end{array} & \text { CS, } \mathrm{N}=964 \\ \begin{array}{l}\text { Paillard-Borg } \\ \text { et al. (2009) }\end{array} & \text { CS, } \mathrm{N}={ }_{\mathrm{I}} 623 \\ \text { Parker (1996) } & \text { CS, } \mathrm{N}=5 \mathrm{I} \\ & \\ \begin{array}{c}\text { Patterson } \\ \text { (1996) }\end{array} & \text { CS, } \mathrm{N}=60\end{array}$

I Domain: combined 'daily and recreational activities' (conversation with family and with friends, relaxing at home, eating meals, working, bathing, physical exercise, watching TV, listening to music, walking, reading, playing with animals, singing, gardening, travelling, fishing, gambling, joining club activities);

pleasantness of activities

5 Domains: I. mental; 2. social; 3. physical; 4. productive; 5 . recreational activity

4 Domains: I. cognitive (e.g. reading, painting, writing, prayer etc.); 2. social (time with friends, church, clubs, games with others etc.); 3. physical (yard/ garden, swimming, walking, working etc.); 4. crafts/hobbies not requiring social interaction (TV, cooking, shopping, collecting, travelling, embroidery,

knitting etc.)

4 Domains: I. home-centred (reading, watching TV, gardening); 2. communitybased; 3. social (talking with family and friends on the phone, visiting family, talking with neighbours); 4. outdoor leisure (hunting, camping, boating, fishing, attending bars/nightclubs, membership at cultural and sporting clubs) physical health on activity participation in five domains

Life satisfaction

Philadelphia Geriatric Center Morale

Scale; Happiness score

Stress (anxiety)
Ratings of pleasantness of three activities significantly correlated with Morale

Scale: travel, eating meals out,

conversation with family.

Pleasantness ratings in many activities predicted Happiness score.

Participation in mental, social and productive activities associated with better cognitive functioning. Productive, physical and mental activities associated with better health and physical

functioning. Women and oldest old had fewer recreational, productive and mental activities, and men more.

No significant relationships.

Higher total scores on Leisure Activity Scale (calculated by the number and frequency of participation in 28 leisure activities) were negatively correlated with stress. 


\begin{tabular}{|c|c|c|}
\hline Authors (year) & Design & Activity domains \\
\hline $\begin{array}{l}\text { Ritchey, } \\
\text { Ritchey and } \\
\text { Dietz (200I) }\end{array}$ & $\mathrm{CS}, \mathrm{N}=\mathrm{Iog} 2$ & $\begin{array}{l}3 \text { Domains: I. formal (attending meetings } \\
\text { irregular work, volunteer work); } \\
\text { 2. informal (talking on the phone, active i } \\
\text { sports, contact with children, contact wit } \\
\text { mother, contact with father, helping } \\
\text { others, providing care, helping with } \\
\text { problems); } 3 \text {. solitary (hours per week } \\
\text { with TV or radio, reading, or doing } \\
\text { housework) }\end{array}$ \\
\hline $\begin{array}{c}\text { Silverstein and } \\
\text { Parker (2002) }\end{array}$ & LS, Io years, $N=324$ & $\begin{array}{l}6 \text { Domains: I. culture-entertainment; } \\
\text { 2. productive-personal growth; } \\
\text { 3. outdoor-physical; 4. recreation- } \\
\text { expressive; } 5 \text {. friendship; } 6 \text {. formal-grou }\end{array}$ \\
\hline $\begin{array}{l}\text { Strain et al. } \\
(2002)\end{array}$ & $\mathrm{LS}, 8$ years, $\mathrm{N}=3^{80}$ & $\begin{array}{l}\text { I Domain: leisure (dining out, outdoor yar } \\
\text { work, playing cards, reading, shopping, } \\
\text { theatre, movies/spectator sports, travel, } \\
\text { walking, watching television, and church } \\
\text { services) }\end{array}$ \\
\hline $\begin{array}{l}\text { Walter- } \\
\text { Ginsburg et al. } \\
(2005)\end{array}$ & $\mathrm{LS}, 3-4$ years, $\mathrm{N}=960$ & $\begin{array}{l}3 \text { Domains: I. physical (walking, } \\
\text { gardening); } 2 \text {. solitary ( } \mathrm{TV} \text {, reading); } \\
\text { 3. religious attendance; continuation } \\
\text { of activity }\end{array}$ \\
\hline
\end{tabular}

Outcome measures

Key findings ${ }^{1}$

\section{Wellbeing (nine}

aspects) including life

satisfaction,

happiness, self-

esteem, depression

Informal social activity showed a

relationship with more aspects of

wellbeing than did formal and solitary

activity. Visits with friends, attending

religious services, taking walks and

gardening showed the most

relationships to wellbeing.

Quality of life

Increased activity participation across domains improved quality of life over time. The most popular activities at baseline (gardening, hobbies, reading books) did not change after a decade.

Self-rated health. ADL and IADL functioning

Time to survival

Continuation of activities after eight year was associated with having better or the same self-rated health as baseline, having the same or fewer ADL/IADL

limitations. Watching TV and reading

were the most likely to be continued.

Losing a partner over the eight years predicted fewer continued activities.

Religious attendance and physical activity were associated with longer survival

for women and solitary activities

were associated with increased survival for men. 


\begin{tabular}{|c|c|c|c|c|}
\hline $\begin{array}{l}\text { Warr, Butcher } \\
\text { and } \\
\text { Robertson } \\
(2004)\end{array}$ & $\mathrm{CS}, \mathrm{N}=\mathrm{II} 67$ & $\begin{array}{l}6 \text { Domains: I. family/social; } 2 . \text { church/ } \\
\text { charity; } 3 . \text { home and garden; } \\
\text { 4. reflection/learning; } 5 . \text { music/drama; } \\
\text { 6. sports. }\end{array}$ & $\begin{array}{l}\text { Affective wellbeing, } \\
\text { life satisfaction }\end{array}$ & $\begin{array}{l}\text { Family/social and Home/garden activities } \\
\text { were associated with affective wellbeing; } \\
\text { Family/social and Church/charity } \\
\text { activities were associated with life } \\
\text { satisfaction; Family/social were more } \\
\text { important for women in this study. }\end{array}$ \\
\hline $\begin{array}{l}\text { Werngren- } \\
\text { Elgstrom, } \\
\text { Brandt, and } \\
\text { Iwarsson } \\
(2006)\end{array}$ & $\begin{array}{l}\mathrm{CS}, \mathrm{N}=45 \text { deaf older } \\
\text { adults }\end{array}$ & $\begin{array}{l}2 \text { Domains: I. productive (domestic } \\
\text { activities, caring for family and house, } \\
\text { work); } 2 . \text { leisure (physical, cognitive, social } \\
\text { within the deaf club, social outside the } \\
\text { deaf club) }\end{array}$ & $\begin{array}{l}\text { Depressive and } \\
\text { ill-health symptoms, } \\
\text { perceived health, } \\
\text { subjective wellbeing }\end{array}$ & $\begin{array}{l}\text { Productive activities were related to health } \\
\text { and depressive symptoms - older deaf } \\
\text { people in better health and without } \\
\text { depression were more likely to be caring } \\
\text { for family and house or engaging in } \\
\text { productive activities; total number of } \\
\text { activities were related to perceived health } \\
\text { and subjective wellbeing. }\end{array}$ \\
\hline $\begin{array}{l}\text { Zimmer and } \\
\text { Lin (I996) }\end{array}$ & CS, $N=4049$ & $\begin{array}{l}4 \text { Domains: I. physical (sports, walking, } \\
\text { gardening); 2. creative (games, hobbies, } \\
\text { reading, handicrafts); } 3 . \text { contemplative } \\
\text { (worshipping, thinking); 4. social } \\
\text { (socialising); satisfaction with social } \\
\text { contacts }\end{array}$ & Life satisfaction & $\begin{array}{l}\text { For both men and women, satisfaction with } \\
\text { social contacts and physical activities were } \\
\text { positively associated with life satisfaction, } \\
\text { after controlling for relevant variables. } \\
\text { For women only, contemplative activities } \\
\text { were negatively associated with life } \\
\text { satisfaction. }\end{array}$ \\
\hline
\end{tabular}

Notes: ADL: activity of daily living. IADL: instrumental activity of daily living. I. Focusing on activity domains related to wellbeing, moderators or mediators. Design: LS: longitudinal study. CS: cross-sectional study. 2. Sample sizes for individual countries from I,854 to 2,417. 3. One wave from Terman LS. 4. Satisfaction with health, functional limitation, depressive symptoms, and life satisfaction. 5. Disability, cognitive impairment, functional limitations, depressive symptoms. 6. Defined by lack of disability, cognitively intact, non-depressed mood, independence in ADLs. 4harity; 3. home and garden;

6. sports.

within the deaf club, social outside the

perceived health,

6. Defined by lack of dishility, cognitively intat, non-depresed mood, independence in ADts.
Family/social and Home/garden activities Family/social and Church/charity satisfaction; Family/social were more ortant for women in this study. and depressive symptoms - older deaf people in better health and without for family and house or engaging in activities were related to perceived health and subjective wellbeing.

social contacts and physical activities were after controlling for relevant variables.

For women only, contemplative activities were negatively associated with life satisfaction 
Whereas the domain sets describe groups of individual categories, we define dimensions as the overarching aspects of activity participation that are represented in the classification. For instance, the domain set formal, informal and solitary highlights two dimensions of the social context, tapping into both the solitary-social dimension and the formal-informal social dimension. In contrast, the domain set of productive and leisure highlights the activity's purpose along the dimension of productivity, i.e. the practical or instrumental functions of the activity, possibly including economic value, as distinct from a recreational or enjoyment purpose or function. Leisure activity may serve several purposes, but at its most basic definition, is done solely for the enjoyment of the actor. Also, leisure activity implies something done by choice. An activity measurement scheme highlighting the two domains productive and leisure therefore encompasses both purpose and choice. (The dimension of discretionary versus obligatory is a more formal way of expressing this aspect of activity, namely how much it is freely chosen.) Productivity versus leisure would not capture the social dimension, however, since both productive and leisure activities may be either social or solitary. A number of other overarching dimensions are reflected by activity domains and domain sets, such as spatial context, in the domains travel or fishing and hunting, creativity in domains such as music making, and arts and crafts, or self- versus other-directedness in diverse domains such as volunteer work, community service, or solitary hobbies.

Activity domains may also reflect other demands upon the participant, sometimes unintentionally. For instance, physical demand or mobility issues are reflected in the physical or fitness activity domains. It is also possible that physical mobility demand is reflected in measures of formal versus informal social activities, as it is more difficult to participate in formal social activities such as attending clubs without physical mobility and good functioning. Likewise, intellectual demand is reflected in a number of activities such as reading, games of skill, hobbies or attending cultural activities.

The reviewed studies fell into two major categories with regard to how activity domains were derived. Domains could be created a priori, or activity lists could be subjected to factor analytic techniques to enable categories to emerge empirically. Both methods have their merits and limitations. The straightforward a priori method uses background knowledge about the lifestyles of older adults from a given perspective about which properties of activity are important for older adults, and applies the face validity criterion to place activities in the categories. These decisions, however, may be biased by the researchers' presumptions that may be inappropriate for the sample. On the other hand, empirical methods such as factor analysis that categorise activities together according to their 
endorsement by the same individuals may result in groupings of relatively unrelated activities that nevertheless tend to co-vary in certain types of individuals. For example, people who like reading may also like gardening, both of which are usually solitary activities, yet differ in terms of the level of demand and the possible benefits to mind and body. Activities may not be correlated in consistent ways. Because the choice to participate in a given activity means there is less time for another activity to be done, to some extent, the choice of activities in which to participate is a zero-sum situation. In the phrase of Marottoli et al., 'an aggregated summation of discrete (in some cases unrelated) activities constitutes a reasonable index of the amount of activity in which a participant engages' (2000: S336). $_{3}$. This argues against the need for factor analytic techniques in activity measurement.

Variability in the ways activity and 'engagement in life' are operationalised and measured makes interpretation of the literature problematic (Mendes de Leon 2005; Parslow et al. 2006; Ritchey, Ritchey and Diaz 200I). According to Kerby and Ragan, 'despite the widespread study of activities and ageing, little attention has been given to classifying activities. Most studies simply classify with an ad hoc approach. Comparisons across studies are difficult.... In addition, a weakness of this literature is the absence of an empirical basis for the classification' (2002: i 8). Possible criteria for 'successful' measurement of social and leisure activity in older adults might include the exhaustiveness of the domains in covering the range of social and leisure activities, clarity and exclusivity of categories used, as well as how theoretically relevant and meaningful the distinctions or dimensions are. Do they distinguish the aspects that are important in terms of activity content, social context, demand on the individual, and personal choice or meaning?

Among the best-conceptualised models of activity classification were several that combined two or more dimensions of the activity in their measurement scheme. For instance, the functional domains of social, leisure and productive were overlaid with the dimension of demand upon the participant (Everard et al. 200o), producing four final categories: instrumental, social, high-demand leisure and low-demand leisure. Through principal component analysis, Lennartsson and Silverstein (200I) derived four underlying factors along two dimensions: solitary-social and sedentary-active. The resulting categories were as follows: social/friendship, social/cultural, solitary/ sedentary and solitary/active. Both of these studies parsimoniously differentiated the content, function and demand aspects, as well as the social-solitary dimension, with dual categorisation.

Another exemplary activity classification system distinguished regenerative activities (those that have to be carried out to survive; 
self-maintenance) from discretionary activities (done by choice) (Maier and Klumb 2005). The discretionary category was further subdivided by the 'third-party criterion' that asks, 'Could someone else do this on behalf of the person (productive activity), or is the purpose for the person to do this him or herself (consumptive activity)'? The resultant activity domains in this study are named regenerative, productive and consumptive, taking into account dimensions of choice and function. To address the social dimension, Maier and Klumb further subdivided the consumptive category into social and solitary activity, and then disaggregated the social into several of the most common specific activities among older adults - face-to-face talks, phone calls, making visits, other social interaction. This study presents one of the most complete categorisation schemes among those reviewed.

\section{Findings on activity and subjective wellbeing, health or survival}

The majority of studies reviewed showed positive associations between activity participation and psychosocial wellbeing, health or survival. Most of the studies reported differential associations by type of activity or by personal characteristics such as gender of participants. Some of the studies teased out associations with specific domains or even specific activities, while others used summary measures of activity participation, such as a general 'leisure' category. In studies that examined specific activity types, various domains were reported to positively relate to at least one measure of wellbeing, health or survival. The outcomes noted in Table I were those reported as statistically significant in the study. From these outcomes, we created a summary table of findings regarding the major categories of activity that were associated with wellbeing, health or survival, in crosssectional or longitudinal studies (see Table 2). Taking all the studies into account, the summary domain of social activities (all social activities, including unspecified and specified, a mix of both informal and formal), followed by physical and unspecified leisure activities had the most associations with wellbeing, health or survival (in $26,{ }_{5}$ and I4 studies, respectively). Intellectual/cultural and solitary activities had significant associations in eight studies. Productive/instrumental and spiritual/service activities each accumulated evidence for associations in fewer studies. Among the longitudinal studies, social, physical and leisure activities predicted positive outcomes in the most studies: eight, seven and six, respectively.

The differential effects of activity on specific types of wellbeing or health variables were the focus of several studies. For instance, Ritchey, Ritchey and Dietz (200I) used nine separate measures for different aspects of 
T A B L E 2. Activity summary domains associated with wellbeing, health or survival in 42 studies

\begin{tabular}{lccc}
\hline Domains & $\begin{array}{c}\text { Longitudinal studies } \\
(\mathrm{N}=24)\end{array}$ & $\begin{array}{c}\text { Cross-sectional studies } \\
(\mathrm{N}=\mathrm{I} 8)\end{array}$ & Total \\
\hline Social: & 8 & & \\
Informal & $\mathrm{I}$ & 3 & $\mathrm{II}$ \\
Formal & 5 & $\mathrm{I}$ & 2 \\
Unspecified & 8 & 6 & $\mathrm{I} 3$ \\
Leisure/consumptive & 5 & 3 & $\mathrm{I} 4$ \\
Intellectual/cultural & 8 & 7 & 8 \\
Physical & 3 & 5 & $\mathrm{I} 5$ \\
Solitary & 3 & 4 & 8 \\
Productive & 3 & $\mathrm{I}$ & 7 \\
Spiritual/service & 44 & 38 & 4 \\
Total domains & 6 & 2 & 82 \\
Quality/satisfaction & & & 8 \\
\hline
\end{tabular}

wellbeing to show that informal social activities positively influenced the greatest number of wellbeing measures. Warr, Butcher and Robertson (2004) found that family/social, home/garden and church/charity activities were most highly associated with affective wellbeing and life satisfaction. Werngren-Elgstrom, Brandt and Iwarsson (2006) found that productive activities were associated with better health and fewer depressive symptoms, but total activities related to subjective wellbeing.

More complex research designs tested questions beyond the straightforward activity-wellbeing relationship. Silverstein and Parker (2002) reported on ten-year longitudinal data that allowed them to follow increases or decreases in activity participation for various activities. They found that older Swedes withdrew from leisure activities over time, but many of the lost activities were replaced by alternatives, and some respondents actually increased the number of activity domains in which they participated. Cultural-entertainment, outdoor-physical, and formal group activities showed significant reductions, while friendship activities and reading were among those maintained at a similar level. In addition, they found that maintaining or increasing one's range of activities was a buffer against the detrimental effects of functional impairments, widowhood or lack of family support, pointing to the complexity of the relationship between activity participation and types of wellbeing. Strain et al. (2002) also reported positive effects of continuing activities, while Nimrod (2008) focused solely on newly added activities - innovation - which was shown to be associated with greater life satisfaction. Another longitudinal study identified three patterns of activity participation among older adults and that those 
who fit the pattern with the most informal social activity had less initial depression and decreasing depression over time (Hong, Hasche and Bowland 2009).

\section{Causal inferences}

Cross-sectional studies comprise the bulk of the evidence base for the association between activity participation and wellbeing or health. These studies demonstrate associations while controlling for other potential predictors of wellbeing, but cannot establish temporal order. Eighteen longitudinal studies were identified that tested relationships between social and leisure activity participation and wellbeing, health or survival among older adults. Longitudinal research is a superior vehicle for studying relationships with long-term effects, and is particularly germane to research on ageing that seeks to examine 'determinants of intra-individual change over time' (Schaie and Hofer 2001: 55). However, in naturalistic research on the effects of activity, drawing causal inferences from longitudinal studies may be limited by variations in starting points with regard to activity, health or wellbeing levels, and resultant measured or unmeasured moderation effects, or floor or ceiling effects on the potential for activities to influence wellbeing. Thus, although as Menec stated, 'implicit in this discussion is that activity promotes health and wellbeing rather than vice versa' (2003: S75), selection effects regarding health or socio-economic status may mean that those with poorer health or fewer resources cannot participate in as many activities, rather than that fewer activities actually makes for worse health or wellbeing (Agahi and Parker 2008). Janke, Nimrod and Kleiber $(2008 b)$ noted that their study offered more support for wellbeing influencing activity than activity influencing wellbeing.

As a number of these authors have noted, it is likely that there are reciprocal effects between social participation and health or wellbeing that cannot be easily untangled, whether the study is longitudinal or crosssectional. Interpretations of any of these studies can only address the research questions answered by the design, measures and analytical methods, which vary considerably among the studies reviewed. Even though the studies controlled for many factors that might influence wellbeing, they cannot completely control for the interactive and reciprocal nature of health status, personality factors, activity opportunities, activity preferences and wellbeing measures. Even longitudinal studies using death as the ultimate outcome measure may not tell an easily interpretable story. According to Mendes de Leon, '[death is] the end result of often multiple disease processes that have evolved over years, if not decades, and interact with each other in complex ways. So, if we find measures of social 
engagement to be predictive of survival, what does this really mean? How did social engagement affect this process?' (2005: 65).

\section{Moderating factors}

Understanding the influence of personal characteristics upon the activity/ wellbeing relationship is an important goal that some recent studies have addressed by examining interaction or moderating effects of descriptive variables. Gender was the most commonly tested participant characteristic, appearing in about one-quarter of the studies, with enough evidence to suggest that there are distinct activity and wellbeing or survival relationships for males and females. For example, Lennartsson and Silverstein (200I) found that solitary-active activities reduced mortality risk for males but not for females, while Warr, Butcher and Robertson (2004) found that women's family and social domains influenced their wellbeing more than men's. Agahi and Parker (2008) likewise found that women's mortality risk decreased with more informal and formal social activity, whereas men's survival was helped more by solitary hobbies and gardening. In a more complex conceptualisation, Harlow and Cantor (I996) found that being retired raised the importance of activity for wellbeing more among men than women. In one of the only studies that examined a single activity, reading, Jacobs et al. (2008) found that daily reading at baseline reduced mortality risk for men, but not women, after controlling for other factors. Walter-Ginzburg et al. (2005) found very different results for old-old men and women in Israel; men fared better who participated in more solitary leisure activities and women fared better who reported more physical activity and attendance at religious services. In a similar finding for Taiwanese elders, Zimmer and Lin (1996) found that women's wellbeing was negatively influenced by greater contemplative activity.

In the Silverstein and Parker (2002) study discussed earlier, widowhood, higher functional limitations, and lower family support each moderated the longitudinal effect of activity participation on wellbeing. Age, being in the 'old-old' category, was found to positively moderate satisfaction with home-based activities (Fortuijn et al. 2006) and negatively moderate degree of leisure activity (Lampinen et al. 2006), partly through its association with lower mobility and chronic illness. Klumb (2004) found that the influence of social context on positive affect was moderated by proportion of time individuals spent alone, i.e. those who were alone less often were more positively influenced by being in the company of others. She also found that neuroticism moderated the relationship of social participation on positive affect, reducing this relationship. Depression status at baseline was another moderating variable in a longitudinal study by Glass et al. (2006). 
They found that fewer depressive symptoms at baseline resulted in less of an impact of activity on depressive symptoms at subsequent waves.

\section{Mediating factors}

The influence of intervening variables or mediating effects was examined in only a few studies. The purpose or motivation for engaging in social and leisure activities was shown to have an influence on the activity/wellbeing relationship. Six reason domains developed by Everard (I999) were quite exhaustive and clear, and results determined that 'social' reasons predicted the highest level of wellbeing. Herzog et al. (1998) looked at a quality they called 'agentic self-concept' similar to personal mastery, which they found to mediate positively the activity/wellbeing relationship, along with a social self-concept, which had less of a mediating effect. Mobility status reportedly mediated the effects of activity on wellbeing or health in at least one study (Lampinen et al. 2006).

Evaluations or appraisals of social activity were included as mediators in the conceptual frameworks of several studies. Social relationship quality and supportiveness were found to be important mediators in the two studies by Litwin (2000, 2006). Perception of one's activity level as 'enough' (Hong, Hasche and Bowland 2009), satisfaction with leisure activities (Nimrod and Adoni 2006), the perceived value of activities (Katz and Yelin 200I; Neugebauer, Katz and Pasch 2003), or 'activity selfevaluation' (Mullee et al. 2008) were all found to be influential variables in the activity/wellbeing relationship.

\section{Discussion and theoretical implications}

This review of recent studies from a number of countries and cultures demonstrates that social, leisure and productive activities each have significant associations and predictive relationships with aspects of wellbeing for older adults. Although differences in definition and measurement make it difficult to draw inferences about this body of evidence, methodologically rigorous studies generally find positive associations between activity and wellbeing. Arriving at a more comprehensive framework to describe the mechanisms of the effects of social and activity participation on wellbeing will require measures of activity to be better standardised and to take into account the dimensions of purpose, context and demand on the individual. Optimal measures of social and leisure activity should clearly specify the 'active ingredients' that the researcher wishes to examine and identify categories that are mutually exclusive. As noted in this review, 
a promising method for achieving this may involve classifying each activity by two or more dimensions, such as social/active, social/passive, and so on (e.g. Lennartsson and Silverstein 200I).

The reviewed studies in the aggregate provide support for a central aspect of the activity theory of ageing - that informal social participation, through activities such as visiting with friends, has a consistently positive relationship with wellbeing in later life. In their seminal 1972 article, Lemon, Bengtson and Peterson described the theory as the 'social activity theory' and emphasised social intimacy and role supports as the major processes to be understood. Although many of the recent articles reviewed have strayed from this central idea of activity theory in order to examine and compare more types of activity, it is still social activity that has the most evidence in support of its association with positive wellbeing. In several of the studies, informal social activity or social intimacy was shown to be the variable with the greatest independent effect upon wellbeing outcomes ( $c f$. Everard I999; Litwin and Shiovitz-Ezra 2006; Maier and Klumb 2005; Ritchey, Ritchey and Dietz 200I; Warr, Butcher and Robertson 2004). The social intimacy inherent in certain activities appears to be a very important, if not the most important, aspect of engagement that influences wellbeing.

In addition to informal social activity, several other types of activity are found to be related to wellbeing, health or survival, which suggests that activity's influence on wellbeing takes multiple pathways. We may surmise that social activity affects wellbeing or survival by reducing the risks of social isolation and by supplying emotional intimacy, socio-emotional support, reinforcement for one's self-concept and social roles, and the sense of being valued. On the other hand, productive activity may influence health and wellbeing through satisfaction with outcomes, economic gains, mental stimulation, comforting personal routines, sense of purpose, and increased self-efficacy or self-esteem (Wahrendorf et al. 2008). Recreational or leisure activities may affect wellbeing through their intellectual or physical demands (e.g. challenging crossword puzzles), through enjoyment and pleasure in the company or the surroundings, and through the reinforcement, again, of one's self-concept, as with 'I am a good golfer; I can still bake a nice homemade pie'. Activity theory, while a reasonable shorthand, may be inadequate to explain these subtle relationships.

In refining theories of ageing, critical gerontology examines existing research through a lens informed by previous theories and research, as well as the contemporary social and policy context (e.g. Martinson and Minkler 2006). Amidst improvements in quality of life and the 'compression of morbidity' in old age, there has also been some controversy 
about the universal prescription of activity in late life or, as coined by Ekerdt (I986), 'the busy ethic', which holds older people to a standard of keeping busy, or risk being less valuable members of society. In the recent discourse on productive ageing and civic engagement, social gerontologists have critically examined the expectation that older adults be productive citizens, raising the possibility that these goals for older adults may do more to serve society than to enhance the good of the older person (Holstein 2006; Martinson and Minkler 2006). This suggests that sweeping generalisations about the relationship of activity to wellbeing and health may not be appropriate, with implications for both policy and psychosocial practice (Adams 2004; Katz 2000).

Newer activity-related theories such as socio-emotional selectivity (SES; Carstensen I992; Frederickson and Carstensen 1990), and Selection, Optimization and Compensation (SOC; Baltes and Baltes I990; Freund and Baltes 1998) espouse successful ageing through adaptation, focusing particularly on selection of appropriate social and leisure activities (Adams 2004). SES suggests that these changes occur through the selection of social partners to provide the greatest level of comfort and reliability, supporting the importance of informal, reliable, intimate social context, whereas SOC focuses on maintaining everyday competence in activities selecting and optimising activity choices, while compensating for areas that are less strong. Studies specifically designed to test the SOC model (Janke and Davey 2006; Lang, Rieckmann and Baltes 2002) have reported indications of selectivity of leisure pursuits, narrowing the range of activities, and substituting (compensating) by replacing an effortful activity with something more manageable. While each of these theories explains certain aspects of the how and why of changes in activity participation, neither precisely addresses the kernel of activity theory, that maintenance of activity and social engagement enhances wellbeing.

With all of the factors that have been found to influence the relationship of social and leisure activity to health or wellbeing, an updated comprehensive model of activity theory would necessarily be complex. From this current review of relatively recent empirical literature on activity and wellbeing in later life, we can envision some of the important elements of a conceptual model of an extended activity theory of ageing. For example, this literature review suggests that the activity/wellbeing relationship must take into account background variables or moderators, the type of activity, including its content and context, and potential mediators in the form of cognitive appraisals of the activity's benefits to the individual. Among descriptive variables that have been tested as moderators so far in the studies reviewed, we have noted gender, age, physical functioning, depression status at baseline, retirement status, and time spent alone. 
Certainly others may be relevant. The evidence for these findings is at an early stage of development, as gender is the only moderating factor with more than one or two assessment reports.

Our review has suggested that the content and context of activities are key elements when distinguishing various types. The content includes the mental and physical demand or challenge, and the behavioural aspects of the activity. Context is usually operationalised as social context (rather than environmental context, for example). Social context might encompass the simple dichotomy of being alone or with someone else, or being with one or more family members, friends, neighbours or caregivers, and such qualitative factors as the level of warmth or intimacy in the relationship.

Three broadly defined potential mediating constructs representing cognitive appraisals of the activity belong in this comprehensive model, coming between activity content and social context and the wellbeing outcomes: first, degree of choice or discretion of the individual regarding participation in the activity may be important to gauge. The 'agentic selfconcept' noted by one study (Herzog et al. I998) pertains to this important notion of choice and control. This volitional aspect is found in the distinction between regenerative, or obligatory, and discretionary activities (Maier and Klumb 2005), and in the more basic idea of leisure activity: something done by choice. Further, the newer activity-related theories described above, SES and SOC, clearly embrace the choice element in the emphasis on selection by the individual. Unfortunately, many of the domain sets were not able to tease out the issue of choice, by grouping leisure and social activities into larger categories that mixed those that might be freely chosen from those that might be more obligatory. A second mediating factor, again broadly defined, was the value ascribed to or satisfaction found in activity or social participation, measured and noted for its role in several studies (Katz and Yelin 200 ; Mullee et al. 2008; Neugebauer, Katz and Pasch 2003; Nimrod and Adoni 2006). A third set of related mediating factors might be the purpose (Everard I999) or meaning of the activity, shown to be relevant in the activity/wellbeing relationship in fewer studies (Lawton I993; Lawton et al. 2002). The purpose or meaning of the activity also figures into the constructs of productivity, creativity, self-expression and altruism, among others. Very few of the studies in this review explicitly considered an activity's purpose or meaning. Meaning may be one of the more difficult constructs to measure, but it may be crucial in making sense of the activity/wellbeing equation and developing a more comprehensive activity theory of ageing.

Many of the studies reviewed did not include these moderating or mediating factors - no one study could include all - but this critical review 
found rigorous studies that begin to validate and refine the activity theory of ageing. The evidence suggests there are positive effects of informal social context, productive activity, intellectual and cultural activity, and physical activity, but that these effects depend in part on individual characteristics, such as gender, age, life situation, and on cognitive appraisals about the activity. As noted by pioneers in this field over 40 years ago, perhaps the most evident limitation of activity theory is that it does not deal with individual differences and values (Havighurst, Neugarten and Tobin I968). We can now be quite certain that individual characteristics, such as personality or gender, and intervening variables such as choice, meaning, or perceived quality of the activity, play an important role in fostering wellbeing, above and beyond the type of activity or participation frequency. Both the activity and successful ageing paradigms will be strengthened by consideration of the individual older adult, for example by recognising that all activities are not equally valued by all older adults for disparate psychological, developmental and pragmatic reasons. Research endeavours in social gerontology can begin to incorporate these individualising concepts into the design of future studies on activity and wellbeing. With carefully defined measures and more inclusive, well-crafted conceptual models that allow tests of mediating or moderating effects, whether cross-sectional or longitudinal, research on activity and wellbeing should be able to answer questions more definitively and further develop and refine the activity theory of ageing.

\section{References}

Publications included in the literature review are indicated by an asterisk.

Adams, K. B. 2004. Changing investment in activities and interests in elders' lives: theory and measurement. International fournal of Aging and Human Development, 58, 2, 87-108.

*Agahi, N. and Parker, G. 2008. Leisure activities and mortality. Fournal of Aging and Health, 2o, 7, 855-7I.

Aquino, J. A., Russell, D. W., Cutrona, C. E. and Altmaier, E. M. r996. Employment status, social support, and life satisfaction among the elderly. Fournal of Counseling Psychology, 43, 4, 480-9.

Atchley, R. I989. A continuity theory of normal aging. The Gerontologist, 29, 2, I83-190.

Baltes, P. B. and Baltes, M. M. I990. Psychological perspectives on successful aging: the model of selective optimization with compensation. In Baltes, P. B. and Baltes, M. M. (eds), Successful Aging: Perspectives from the Behavioral Sciences. Cambridge University Press, New York, I-34.

Berkman, L. F., Glass, T., Brissette, I. and Seeman, T. E. 200o. From social integration to health: Durkheim in the new millennium. Social Science and Medicine, 5I, 6, 843-57.

Carstensen, L. L. I992. Social and emotional patterns in adulthood. Psychology and Aging, 7, $3,33 \mathrm{I}-8$. 
Diener, E., Suh, E. M., Lucas, R. E. and Smith, H. L. I999. Subjective well-being: three decades of progress. Psychological Bulletin, 125, 2, 276-302.

Ekerdt, D. J. I986. The busy ethic: moral continuity between work and retirement. The Gerontologist, 26, 3, 239-44.

*Everard, K. M. I999. The relationship between reasons for activity and older adult wellbeing. Fournal of Applied Gerontology, r 8, 3, 325-40.

*Everard, K. M., Lach, H. W., Fisher, E. B. and Baum, M. C. 20oo. Relationship of activity and social support to the functional health of older adults. Fournal of Gerontology Social Sciences, 55B, 4, S208-12.

*Fernandez, B. R., Azmarron, M. D. and Ruiz, M. A. 200I. Contribution of sociodemographic and psychosocial factors to life satisfaction. Ageing \& Society, 2 I, I, 24-43.

*Fortuijn, J.vD., van der Meer, M., Burhold, V., Ferring, D., Quattrini, S., Hallberg, I. R., Weber, G. and Wenger, G. C. 2006. The activity patterns of older adults: a crosssectional study in six European countries. Population, Space and Place, I 2, 5, 353-69.

Frederickson, B. L. and Carstensen, L. L. I990. Choosing social partners: how old age and anticipated endings make people more selective. Psychology and Aging, 5, 3, 335-47.

Freund, A. M. and Baltes, P. B. I998. Selection, optimization and compensation as strategies of life management: correlation with subjective indicators of successful aging. Psychology and Aging, I3, 4, 53 ${ }^{-}-43$.

*Glass, T. A., Mendes de Leon, C. F., Bassuk, S. S. and Berkman, L. F. 2006. Social engagement and depressive symptoms in late life: longitudinal findings. Fournal of Aging and Health, $\mathbf{1 8}, 4,604^{-28 .}$

*Glass, T. A., Mendes de Leon, C., Marottoli, R. A. and Berkman, L. F. i999. Population based study of social and productive activities as predictors of survival among elderly Americans. British Medical fournal, 319, 7208, 478-83.

Hagrety, B. M. K., Williams, R. A., Coyne, J. C. and Early, M. R. I996. Sense of belonging and indicators of social and psychological functioning. Archives of Psychiatric Nursing, ro, 4, 235-44.

*Harlow, R. E. and Cantor, N. 1996. Still participating after all these years: a study of life task participation in later life. Fournal of Personality and Social Psychology, 71, 6, I235-49.

Havighurst, R. J. I96r. Successful aging. The Gerontologist, I, I, 8-I3.

Havighurst, R. J., Neugarten, B. L. and Tobin, S. S. I968. Disengagement and patterns of aging. In Neugarten, B. L. (ed.), Middle Age and Aging. University of Chicago Press, Chicago, $\mathrm{I} 6 \mathrm{I}-72$.

*Herzog, A. R., Franks, M. M., Markus, H. R. and Holmberg, D. i998. Activities and well-being in older age: effects of self-concept and educational attainment. Psychology and Aging, I3, 2, I79-85.

Hilleras, P. K., Aguero-Torres, H. and Winblad, B. 200I. Factors influencing well-being in the elderly. Current Opinion in Psychiatry, $\mathbf{1 4}, 4,36 \mathrm{I}-5$.

*Hilleras, P. K., Jorm, A. F., Herlitz, A. and Winblad, B. I999. Activity patterns in very old people: a survey of cognitively intact subjects aged go years and older. Age and Aging, 28, $2, \mathrm{I} 47-52$.

Hogan, M. 2005. Physical and cognitive activity and exercise for older adults: a review. International Fournal of Aging and Human Development, 6o, 2, 95-126.

Holahan, C. K. I988. Relation of life goals at age 70 to activity participation and health and psychological well-being among Terman's gifted men and women. Psychology and Aging, 3, 3, 286-9I.

Holstein, M. 2006. A critical reflection on civic engagement. Public Policy and Aging Report (National Academy on an Aging Society, Gerontological Society of America, Washington DC), I6, 4, I and 2I-I6. Available online at http://www.agingsociety.org/ agingsociety/publications/ [Accessed 28 September 2010]. 
*Hong, S., Hasche, L. and Bowland, S. 2009. Structural relationships between social activities and longitudinal trajectories of depression among older adults. The Gerontologist, 49, I, I-II.

*Jacobs, J. M., Hammerman-Rozenberg, R., Cohen, A. and Stessman, J. 20o8. Reading daily predicts reduced mortality among men from a cohort of community-dwelling 70-year-olds. Fournals of Gerontology: Social Sciences, $\mathbf{6} 3 \mathbf{B}, 2, \mathrm{~S}_{73}-80$.

*Jang, Y., Mortimer, J. A., Haley, W. E. and Graves, A. R. B. 2004. The role of social engagement in life satisfaction: its significance among older individuals with disease and disability. Fournal of Applied Gerontology, 23, 3, 266-78.

*Janke, M. and Davey, A. 2006. Implications of selective optimization with compensation on the physical, formal and informal leisure patterns of adults. Indian Fournal of Gerontology, 2o, I/2, 5 $1-66$.

*Janke, M., Davey, A. and Kleiber, D. 2006. Modeling change in older adults' leisure activities. Leisure Studies, 28, 3, 285-303.

*Janke, M., Nimrod, G. and Kleiber, D. $2008 a$. Leisure activity and depressive symptoms of widowed and married women in later life. Journal of Leisure Research, 40, 2, 250-66.

*Janke, M., Nimrod, G. and Kleiber, D. $2008 b$. Reduction in leisure activity and well-being during the transition to widowhood. Fournal of Women and Aging, 2o, I/2, 83-98.

*Janke, M., Payne, L. and Van Puymbroeck, M. 2008. The role of informal and formal leisure activities in the disablement process. International fournal of Aging and Human Development, 67, 3, 23I-57.

*Katz, P. P. and Yelin, E. H. 20or. Activity loss and the onset of depressive symptoms: do some activities matter more than others? Arthritis and Rheumatism, 44, 5, I194-202.

Katz, S. 2000. Busy bodies: activity, aging and the management of everyday life. Fournal of Aging Studies 14, 2, 135-52.

Kerby, D. S. and Ragan, K. M. 2002. Activity interests and Holland's RIASEC system in older adults. International Fournal of Aging and Human Development, 55, 2, II7-39.

*Klumb, P. L. 2004. Benefits from productive and consumptive activities: results from the Berlin Aging Study. Social Indicators Research, 67, I/2, I07-27.

*Lampinen, P., Heikkinen, R.-L., Kauppinen, M. and Heikkinen, E. 2006. Activity as a predictor of mental well-being among older adults. Aging and Mental Health, ro, 5, $454^{-66 .}$

Lang, F. R., Rieckmann, N. and Baltes, M. 2002. Adapting to aging losses: do resources facilitate strategies of selection, compensation and optimization in everyday functioning? Journals of Gerontology: Psychological Sciences, $\mathbf{5 7} \mathbf{B}, 6, \mathrm{P}_{50 \mathrm{I}}-9$.

Lawton, M. P. I993. Meanings of activity. In Kelly, J. R. (ed.), Activity and Aging: Staying Involved in Later Life. Sage, Newbury Park, California, 25-4I.

*Lawton, M. P., Moss, M. S., Winter, L. and Hoffman, C. 2002. Motivation in later life: personal projects and well-being. Psychology and Aging, I 7, 4, 539-47.

Lazarus, R. S. and Folkman, S. I984. Stress, Appraisal and Coping. Springer, New York.

Lemon, B. W., Bengtson, V. L. and Peterson, J. A. 1972. An exploration of the Activity Theory of Aging: activity types and life satisfaction among in-movers to a retirement community. Journal of Gerontology, 27, 4, $5^{\mathrm{II}-23}$.

*Lennartsson, C. and Silverstein, M. 200I. Does engagement with life enhance survival of elderly people in Sweden? The role of social and leisure activities. Fournals of Gerontology: Social Sciences, 56B, 6, S335-42.

*Li, C., Wu, W., Jin, H., Zhang, X., Xue, H., He, Y., Xiao, S., Jeste, D. V. and Zhan, M. 2006. Successful aging in Shanghai, China: definition, distribution and related factors. International Psychogeriatrics, $\mathbf{1 8}, 3,55^{\mathrm{I}-63}$.

Lim, K. and Taylor, L. 2005. Factors associated with physical activity among older people: a population-based study. Preventive Medicine, 4o, I, 33-40. 
*Litwin, H. 2000. Activity, social network and well-being: an empirical examination. Canadian fournal on Aging, 1 9, 3, 343-62.

*Litwin, H. 2006. Path to well-being among Arab Israelis. Fournal of Cross-cultural Gerontology, 2I, I-2, 25-40.

*Litwin, H. and Shiovitz-Ezra, S. 2006. The association between activity and wellbeing in later life: what really matters? Ageing \& Society, 26, 2, 225-42.

Longino, C. F. and Kart, C. S. 1982. Explicating activity theory: a formal replication. Journal of Gerontology, 37, 6, 713-22.

*Maier, H. and Klumb, P. L. 2005. Social participation and survival at older ages: is the effect driven by activity content or context? European Fournal of Ageing, 2, I, 3I-9.

Marottoli, R. A., Mendes de Leon, C. F., Glass, T. A., Williams, C. S., Cooney, L. M. and Berkman, L. F. 2000. Consequences of driving cessation: decreased out-of-home activity levels. Fournals of Gerontology: Social Sciences, $\mathbf{5 5} \mathbf{B}, 6, \mathrm{~S}_{334}-40$.

Martinson, M. and Minkler, M. 2006. Civic engagement and older adults: a critical perspective. The Gerontologist, 46, 3, 318-24.

Mendes de Leon, C. F. 2005. Social engagement and successful aging. European Fournal of Ageing, 2, I, 64-6.

*Menec, V. 2003. The relation between everyday activities and successful aging: a 6-year longitudinal study. Fournals of Gerontology: Social Sciences, 58B, 2, S74-82.

*Morgan, K. and Bath, P. A. i998. Customary physical activity and psychological wellbeing: a longitudinal study. Age and Ageing, 27, I, 35-40.

*Mullee, M., Coleman, P., Briggs, R., Stevenson, J. and Turnbull, J. 20o8. Self-rated activity levels and longevity: evidence from a 20 year longitudinal study. International Journal of Aging and Human Development, 67, 2, I71-86.

*Neugebauer, A., Katz, P. P. and Pasch, L. A. 2003. Effect of valued activity disability, social comparisons, and satisfaction with ability on depressive symptoms in rheumatoid arthritis. Health Psychology, 22, 3, 253-62.

*Nimrod, G. 2008. In support of innovation theory: innovation in activity patterns and life satisfaction among recently retired individuals. Ageing \& Society, 28, 6, 831-46.

*Nimrod, G. and Adoni, H. 20o6. Leisure-styles and life satisfaction among recent retirees in Israel. Ageing \& Society, 26, 4, 607-30.

*Onishi, J., Masuda, Y., Suzuki, Y., Gotoh, T., Kawamura, T. and Iguchi, A. 2006. The pleasurable recreational activities among community-dwelling older adults. Archives of Gerontology and Geriatrics, 43, 2, I47-55.

*Paillard-Borg, S., Wang, H., Winblad, B. and Fratiglioni, L. 20og. Pattern of participation in leisure activities among older people in relation to their health conditions and contextual factors: a survey in a Swedish urban area. Ageing \& Society, 29, 5, 803-2I.

*Parker, M. D. I996. The relationship between time spent by older adults in leisure activities and life satisfaction. Physical and Occupational Therapy in Geriatrics, I4, I, 6I-7I.

Parslow, R. A., Jorm, A. F., Christensen, H. and Mackinnon, A. 2006. An instrument to measure engagement in life: factor analysis and association with sociodemographic, health and cognition measures. Gerontology, 52, 3, i88-98.

*Patterson, I. 1996. Participation in leisure activities by older adults after a stressful life event: the loss of a spouse. International Fournal of Aging and Human Development, 42, 2, I $23-42$.

*Ritchey, L. H., Ritchey, P. N. and Dietz, B. E. 200r. Clarifying the measurement of activity. Activities, Adaptation and Aging, 26, I, I-2I.

Rowe, J. W. and Kahn, R. L. I997. Successful aging. The Gerontologist, 37, 4, 433-40.

Schaie, K. W. and Hofer, S. M. 200r. Longitudinal studies in aging research. In Birren, J. E. and Schaie, K. W. (eds), Handbook of the Psychology of Aging. Academic, San Diego, California, 53-77. 
*Silverstein, M. and Parker, M. G. 2002. Leisure activities and quality of life among the oldest old in Sweden. Research on Aging, 24, 5, 528-47.

Stanley, M. and Cheek, J. 2003. Well-being and older people: a review of the literature. Canadian Fournal of Occupational Therapy, 7o, I, $55^{-}-9$.

*Strain, L. A., Grabusic, C. C., Searle, M. S. and Dunn, N. J. 2002. Continuing and ceasing leisure activities in later life: a longitudinal study. The Gerontologist, 42, 2, 217-33.

Wahrendorf, M., Ribet, C., Zins, M. and Siegrist, J. 2008. Social productivity and depressive symptoms in early old age - results from the GAZEL study. Aging and Mental Health, I 2, 3, 310-6.

*Walter-Ginsburg, A., Shmotkin, D., Blumstein, T. and Shorek, A. 2005. A gender-based dynamic multi-dimensional longitudinal analysis of resilience and mortality in the oldold in Israel: the cross-sectional and longitudinal aging study (CALAS). Social Science and Medicine, 6o, 8, I705-I5.

*Warr, P., Butcher, V. and Robertson, I. 2004. Activity and psychological well-being in older people. Aging and Mental Health, 8, 2, I72-83.

*Werngren-Elgstrom, M., Brandt, A. and Iwarsson, S. 2006. Everyday activities and social contacts among older deaf sign language users: relationships to health and well-being. Occupational Therapy International, 1 3, 4, 207-23.

*Zimmer, A. and Lin, H. S. I996. Leisure activity and well-being among the elderly in Taiwan: testing hypotheses in an Asian setting. Fournal of Cross-cultural Gerontology, I I, 2, I67-86.

Accepted 30 September 20Io; first published online 3 December 2010

Address for correspondence:

Kathryn Betts Adams, Mandel School of Applied Social Sciences, Case Western Reserve University, Cleveland, OH 44ı6, USA.

E-mail: kathryn.adams@case.edu 